\title{
المنهج التجريبي عند جون لوك وآثاره العلمية المعاصرة
}

Abstract :

أ.م.د. غادة عبد الستنار مهدبي

كابة الآداب / مامعة بنغداد

We know that the philosophy is the systematic attempt to gain insight and understanding of the nature and value of live and reality. And this field consist of many fields. I mean classical and new fields of philosophy.

One of the most important new fields is philosophy of science. This field improve with contemporary age. Which deal with many methods especially with experimental method or empirical way, which in turn dependent on natural sciences and other field. In this research l'll explain how that method made some important achievements in chemistry and medicine sciences in contemporary period.

\section{الاقدمة :}

لا يمكن أن تستقيم المعرفة من دون طريقة أو منهج لاسيما المعرفة العلميـة منها ـ تلك المعرفة التي

تستتد الى قو اعد منهجية ومنظمة ، الغاية منها كثف الحقيقة ثم تحول تللك الحقيقة الى قانون علمي يصدق في كل مكان وزمان ـ الا اذا تطورت المعرفة العلمية والقت بظلال تطور ها وتقدمها على ذللك القانون ليتم تعديله . .

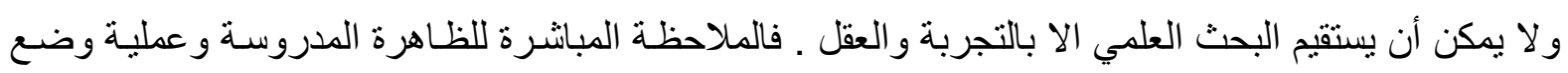
الفروض واختبار ها لإثبات أو للتحقق من قدرتها أو عدم قدرتها في تفسير سلوك الظـاهرة ثم يعمل العقل على العى

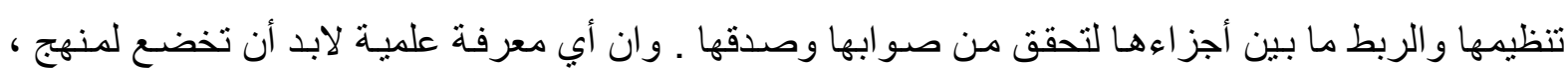
وبغض النظر عن نوع ذلك المنهج .و المقصود بالمنهج الطريقة أو الوسيلة التي يسير بمقتضـاها الباحث أو هي جملة من القواعد السليمة والمنظمة والتي يجب أن يسير عليها الباحث أو العالم أو الفيلسوف بهدف الوصول

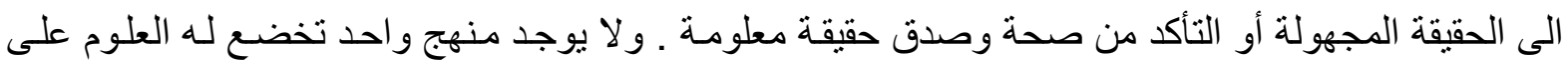
اختلافها وتنوع حقولها ـ بل تتنوع المنـاهج تبعاً للمـادة التي تكون خاضعة لدر استها ـ فهناك المنهج التجريبي و العقلي و المنهج الفرضي الاستنباطي و التاريخي، و النقدي، والتحليلي، و المقارن.. الخ من المناهج الاخرى التي

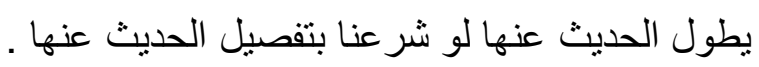

وان سبب تنوع المناهج يعود الى سبيين رئيسيين هما: الأول ، تنوع المنـاهج حسب التطورات العلمية

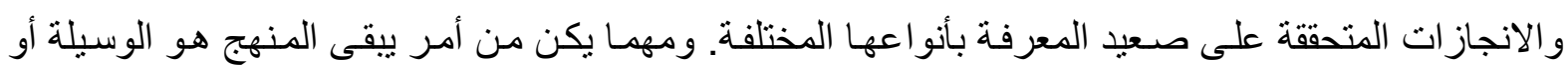

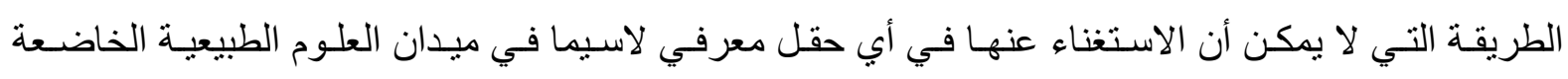
للتجريب. وسوف يكون تركيزي في هذا البحث على المنهج الذي تصطنعه تلك العلوم ـ أب العلوم الطبيعيـــ و أقصد بـه المنهج التجريبي الفلسفي وتحو لاتـه العلميـة. وأثره في اكتثـاف بعض العقاقير الطبيـة في الفترة المعاصرة .

\section{الجذور التأريفية لنشوs المعرفة:}

مما لاشك فيه أن المعرفة بشتى أنو اعها ، و العلوم بمختلف مجالاتها وتخصصساتها نشأت وتطورت منذ بداية التجمعات البشرية على سطح الأرض ـ وان تللك المعارف لم تظهر الا بدافع الحاجـة الى اشباع الحاجات 
اليوميـة والاستعانة بـالأدوات والآلات ، ومن أجل اتقاء أخطار الطبيعـة والسيطرة عليها أيضـاً. ( ( ) فالإنسـان

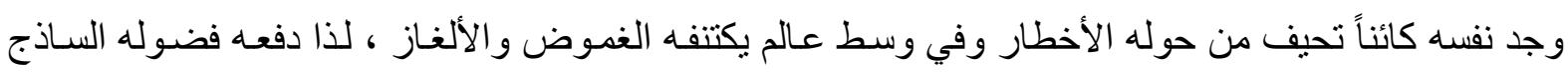
الى طرح تساؤ لات جمة عما حوله من كائنات وموجودات تعيش معه. ناهيك عن سؤ ال مهم شغل فكره وباله منذ القدم وحتى يومنا هذا ، و هو السؤال عن أصل الوجود. (Y) ولم تكن لديه في ذلك الوقت أية خبرة عملية الا بالقدر الذي استطاع تجميعـه عن طريق المشـاهدة ومحاكـاة الحيوانـات ـ وبهذه الطريقـة ــ تقليد تصـرفاتها وسلوكياتها - وكانت تجاربه الذاتية مقتصرة على ما يحيط بـه حيث تعمل التجربـة أو المحاولة و الخطأ دور هـا في توسيع خبر اته ـ. وبهذه الطريقة أخذت تتشأ لديه المعرفة والتي كانت سـاذجة وبسيطة في بداية الأمر وكان ينقصها التبويب و التنظيم - المنهجية كما نطلق عليها حديثاً ـ- فكان يستعين بعقله في الكثف عن طرق تحصيل المعرفة وطرق تجميعها ـ (r) وكان نصيبه من هذا العقل بمثابـة الثـعاع الخافت الذي يعينه فقط على امكانية

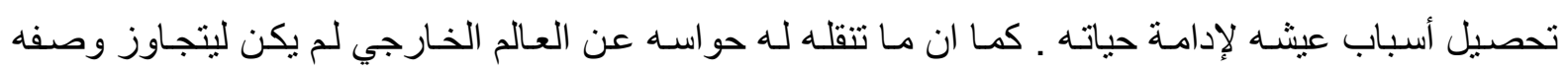

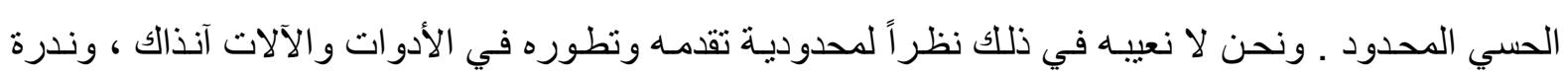
معارفه كذلك ـ (ع ) لذا كان خياله الواسع ينسج له الكثير من الخر افات و الأسـاطير فيرويها لتكون لله عقيدةً

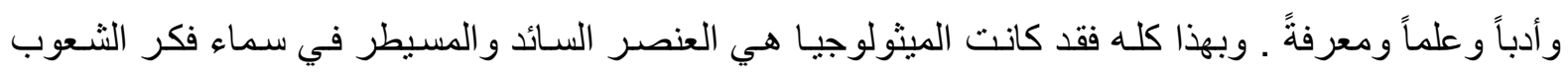

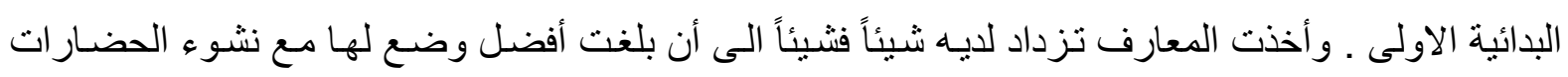

الانسانية . فمع تلك الحضار ات بدأ طابع التنظيم يطر أ على الكثير من تللك العلوم و المعارف و الثقافات .(0) ذلك الطابع الذي كان بمثابة عنصر القوة الذي زود الانسان بطاقة جديدة لارتياد المجهول أكثر فأكثر ، و مكنه في الوقت ذاته من التصدي لأخطار الطبيعة واتقاء شرور ها ـ فعلى سبيل التمثيل نجد أن استخدامه لبقايا العظام وبعض الأحجار ساعدته في مجابهة الطبيعة والكائنات المفترسة و القاتلة. من هنا كانت تللك الامور تمثل

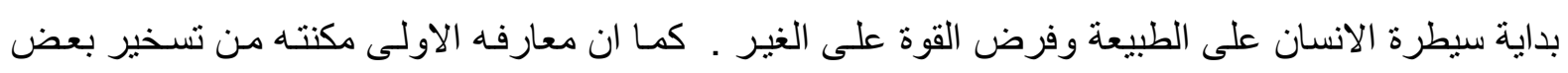

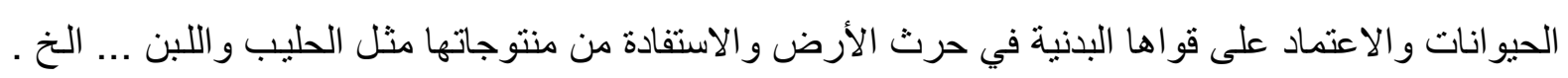
(T) وكانت المرحلة الأخيرة تمثنل بدايـة تطور الآلـة ( الماكنة ) واستخدامها بشكل منظم وهـادف في الحيـاة الانسانية والاجتماعية ـ ولم تقتصر على هذين الجانبين بل تطورت فيما بعد لتطال مجالات اخرى سوف أنشير اليها في سياق الحديث عن تطور المعارف لاحقاً .

\section{هضارات الشرق القديمة :مضارة وادي الرافدين - حضارة وادي النيل إنهوذج)}

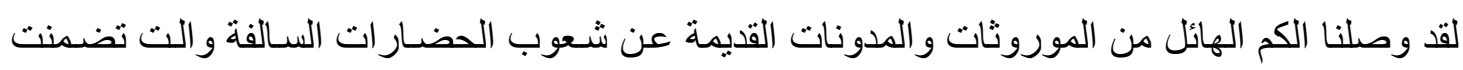

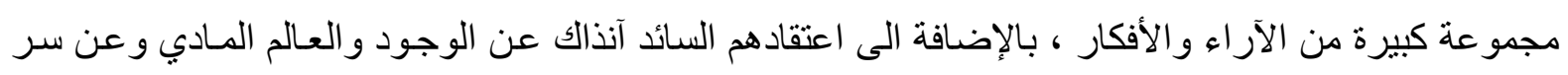

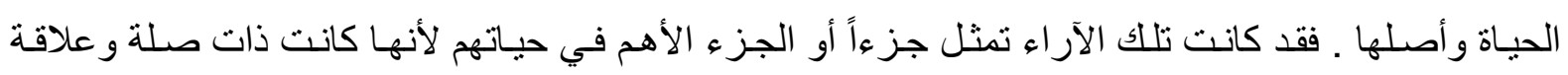

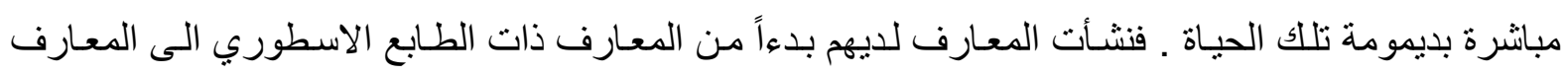

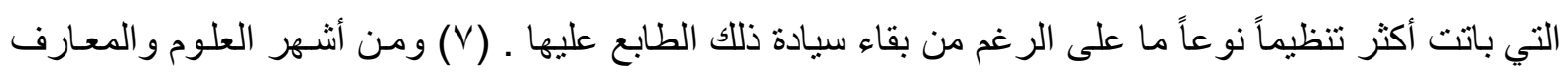
البسيطة التي انبتقت لديهم هي العلوم النظريـة التي نطلق عليها اليوم تسمية العلوم ( النظريـة والتطبيقية ) ، 
ومنها علم الحساب و الهندسة و علم الفلك - الهيئة سابقاً ـ الزراعة ـ الفلاحة سابقاً- و غير ها من العلوم الاخرى

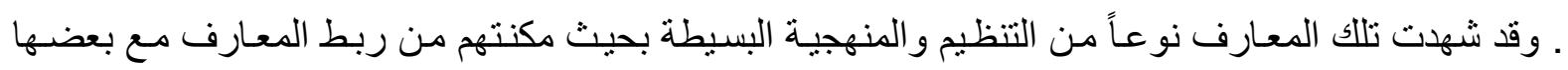
لتصبح أكثر نفعاً.- و هذا خير دليل على عملية التنظيم هذه ـ- فقد أفادوا من علم الفلك في مبدان الملاحـة عندما

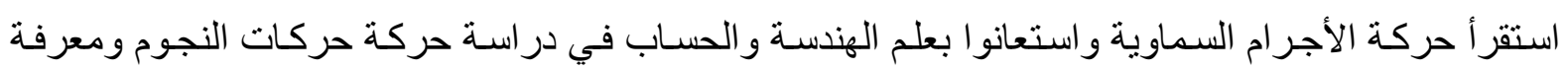
قياس الزمن واستثمروا ذلك في انشاء وشق الترع للإرواء ـ وكانت لديهم القليل من المعلومات الرياضية منها

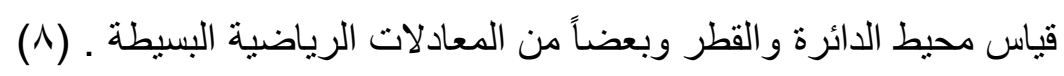

أما عن حضارة وادي النيل العريقة فلم تقل انجاز اتها أهميةً عن حضارة وادي الر افدين ـ فقد نشأت لديهم

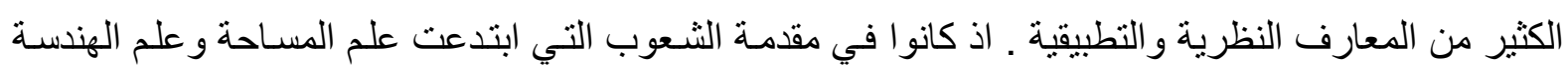

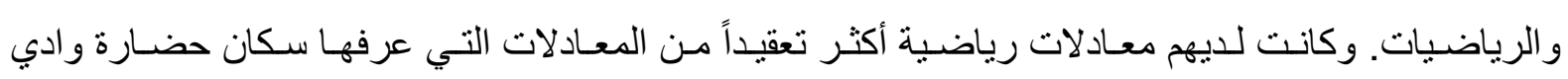

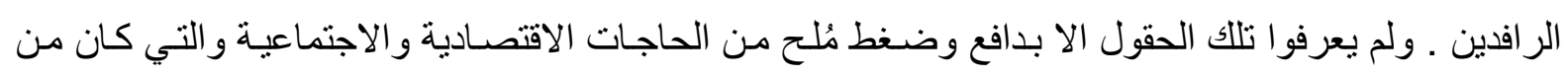
أهمها ، فيضانات وادي النيل ذلك الأمر الذي دفع فر اعنة مصر وملوكها الى الاسر اع بأخذ تدابير سريعة لاتقاء أخطار تللك الفيضانات . فقد توصلوا الى ابتكار أساليب وطرق هندسية لتحديد مساحات الحقول وتتظيم الزراعة و الري ـ وكانوا من أوائل الحضـار ات في استخر اج مسـاحات بعض الأشكال الهندسية منثل المربع و المثلث

و المخروطي و المتساوي الساقين. (9) و وانون

وان جميع تلك المعارف ساعدتهم - لاسيما الرياضية و الهندسية - منها في بناء الاهر امسات التي ماز الت شـامخة حتى يومنـا هذا وهي احدى عجائب الدنيا السبعة . ولم تقتصر الرياضيات و الهندسـة في تثيبيد تلك ولك

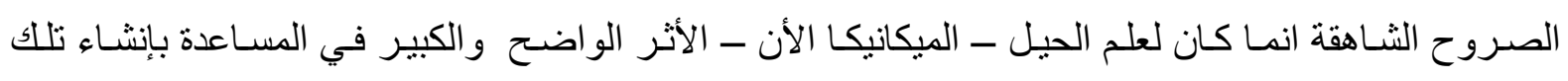
المعالم الأثرية القديمة ـ. اذ استعان العمال آنذاك بر افعات ومكائن جبارة تعينهم على قياس الهرم وزو ايـاه بشكل

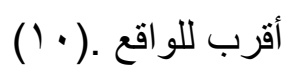

\section{هضارات الغرب القديمهة: (المضارة اليونانية إنموذجا)}

من المعروف عن سكان الحضـارة اليونانيـة قديماً انهم شعوب امتـازت بالأصسالة والتجريد ، و اتسمت حضارتهم يشكل عام بالطابع المتجدد نظر اً لنبوغ عدد من عباقرة ذلك الزمن وفي مختلف الميادين والحقول .

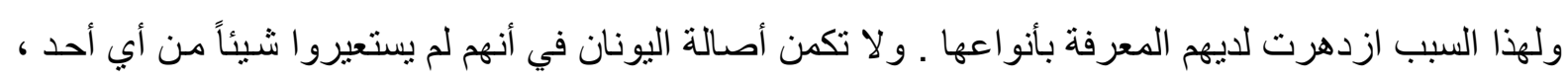

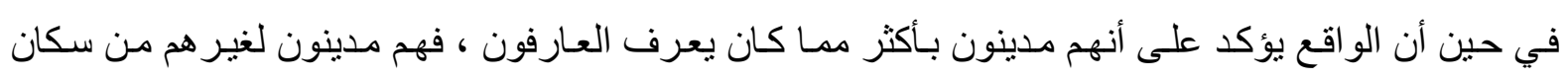

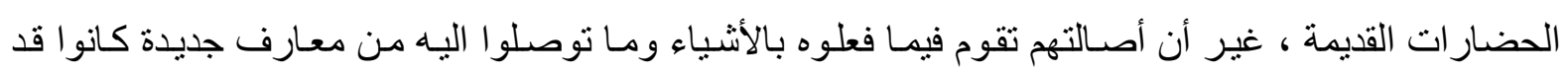

استعارو ها و اقتبسو ها من الآخرين . (I)

كانت بلاد اليونان من البلدان الثرية التي تمتعت بطبيعة خلابـة دفعت بـالكثير من العباقرة وفي مقدمتهم

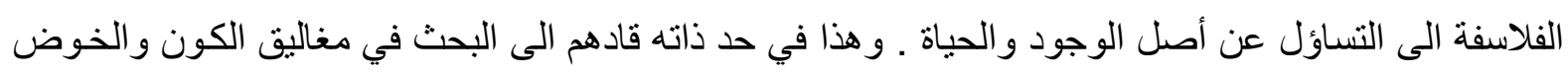

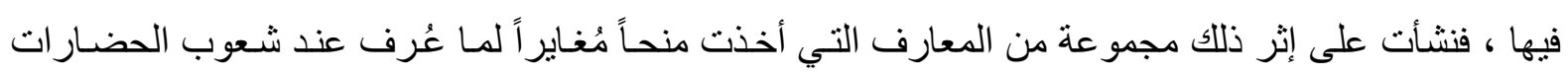
القديمة ـ اذ أن معظم المعارف في وقتها كانت معارف ذات طلبع عقلي و عملي في الغالب ـ أمـا مـع حضـارة 
اليونان فقد حدثت نقلة جديدة عندما أضفى العديد من الفلاسفة والعلمـاء طابعاً أكثر تجريبياً مع تلك المعارف التي استمدوا الكثير منها من سكان وشعوب تللك الحضار ات ـ فأصبحت بذللك علوماً ومعارفاً ذات طابع عقلي ـ عملي أكثر من كونها ذات طابع عملي يكتفي بتحقيق الأغر اض العملية لا غير .

كما ان نظرتهم الى الوجود و الكون - على الرغم من عدم خلوها من الطابع الميثولوجي ـ فقد كانت أقرب الى الو اقع منها الى الخيال ـ وان هذا الأمـر قد تجلى بوضوح مـع اولى المدارس الفلسفية وهي مدرسـة ملطية ( أيونيا ) الطبيعية ذات التوجه المادي - الطبيعي. فقد حاول العديد من فلاسفتها وممثليها تفسير الأشياء

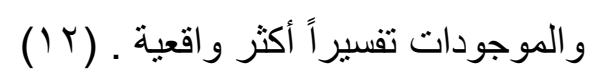

وكان في مقدمة هؤ لاء طاليس الذي فسر تنوع الكائنات بتشخيص القوى الطبيعية والروايـة عن الآلهة

نظر اً إلبها على أنها أشياء معروفة محسوسة ، وحاول الاستقر اء و البرهنة . فهذه النظرة وهذا المنهج همـا الربح

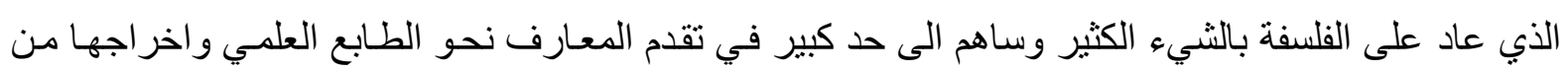

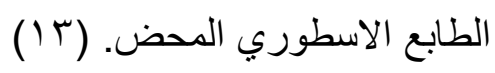

وبـللك تكون هذه المدرسـة المنطلق الأول لانبثـاق المعـارف التجريبيـة القائمسة على الملاحظـة الحسية المباشرة. وان خير من مثلها الى جانب طاليس هو الفيلسوف أنكسيمندريس وهيروقليطس ثم أنباذ وقليس الذي

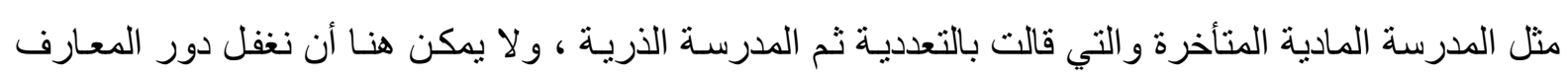

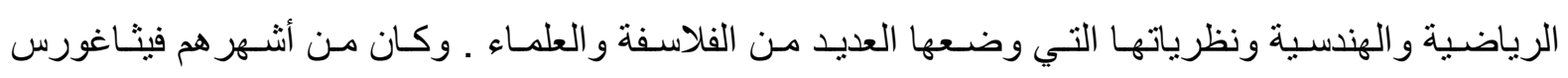

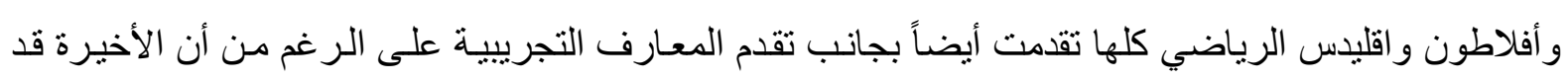

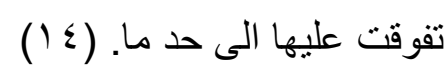

\section{المعرفة في العصور الوسطى ( الهضارة المسيمية - المضارة الاسلاميةية ):}

اذا عدنا الى العصور الوسطى ( المسيحية ) بالذات نجد ان ما عرف عن هذه الحقبة هو أنها حقبة طويلـة

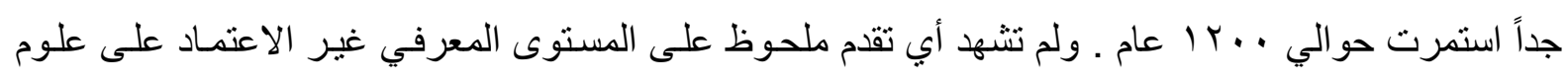
الأقدمين ـ فقد نم رفض أية نظرية علمية أو فكر فلسفي جديد يخالف ما جاء في الكتاب المقدس أو مـا يتعارض مع العلم اليوناني القديم ـ العلم الأرسطوطاليسي ـ الذي وصل اليهم عن طريق حركة الترجمة التي قام بها السريان ، لاسيما أن القساوسة و الرهبان هم من كان يتولى زمام الامور وشؤون البلاد بالكامل في مقابل فقدان العلمـاء و الفلاسفة لدور هم و أهميتهم على الصسيد الاجتمـاعي و العلمي على السواء ـ ـ فقد كانوا الطبقة الأكثر

تضرراً من بطش الكنيسة. (10)

و هذا ما يفسر تأخر المعارف وحقو لها في تللك الحقبة التأريخية المظلمـة . فالفلسفة ظلت تسير في خدمـة الدين على مدار أكثر من ألف عام محاولةً تقديم البراهين والأدلة المنطقية بناءاً على ما قرره الأخير نفسـه ــ أي

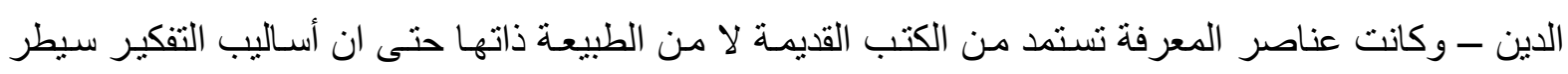
عليها الجدل اللفظي العقيم ـ فقد برع مفكروا ذللك العصر في اقامة الحجج و البراهين اللفظية الخالصـة وتلاعبوا بالاستدلالات الثكية و المغالطات التي تتخذ في ظاهر هـا صبغة منطقية ولكنهم لم يتوصلوا الى أي منهج في ولي 
البحث يعين على معرفة مباشرة . فالألفاظ عندهم كانت حاجزاً يحجب الواقع ومنهجهم الوحيد المُعتمد في

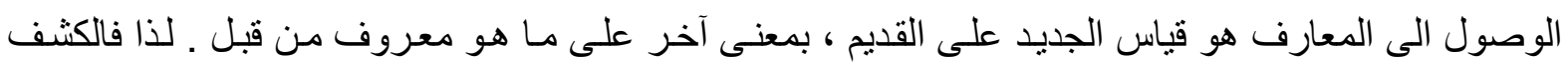

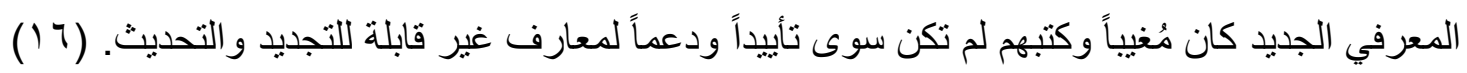

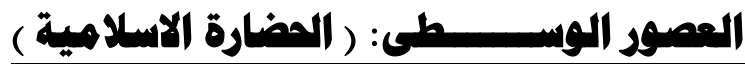

بعد أن توسعت قاعدة المجتمع العربي أخذت تمند لأبعاد واسعة نتيجة الفتوحات العربية التي اتصل على أثر ها العرب و المسلمين بالأمم الاخرى. وكانت الأخيرة قد مرت بتجارب حضـارية مختلفة عبر العصور فبدأ الاختلاط بينها وبين العرب و المسلمين. ومن خلال هذا الاختلاط تسربت الأفكار والفلسفة اليونانية بالإضافة الى ولى ولى

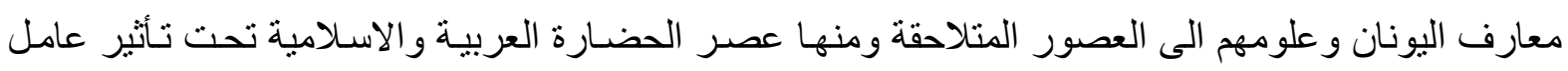
الترجمة الذي نشط على نحو كبير في تللك الحقبة التاريخية التي امتازت بطابعها التجديدي بعكس مـا كانت عليه

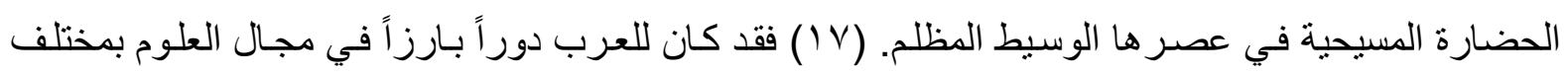

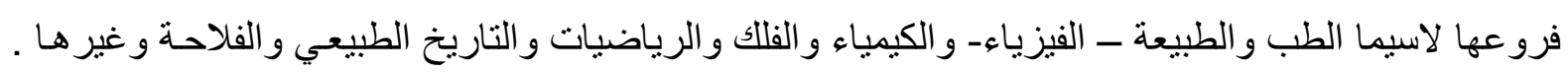
وقد عرف العرب العلم على أنـه امـا معرفـة تجريبيـة أم معرفة صدورية رياضية ، حتى ان بعض المؤرخين

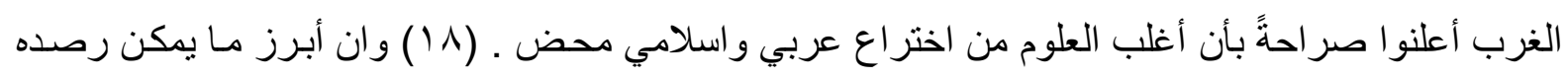
في تمحيص تللك العلوم هو اعتمـادهم في تلك المجالات ـ خصوصـاً في معارفهم التجريبية ـ على الصبياغة العلمية والمنهجية للعلوم البحتة بحيث أسست على أرضية جديدة قائمة على التجريب الصحيح وترفض الخر افة

والاسطورة. (19) (19)

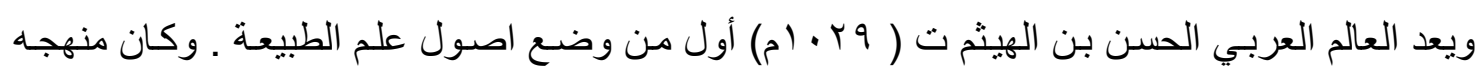

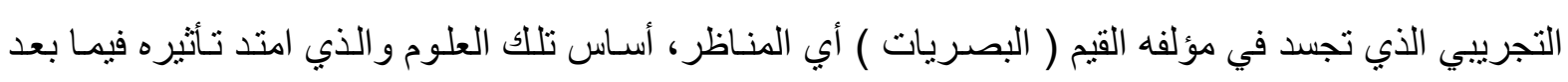

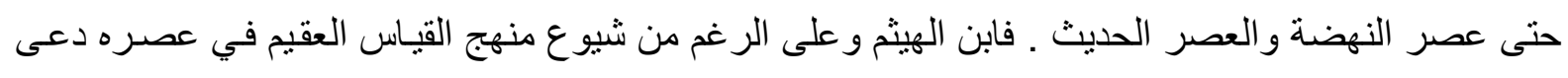
الى ضرورة الاعتماد على المنهج في كل بحث تجريبي والاعتماد على التجربـة التي أطلق عليها اسم الاعتبار في دراسة الظواهر الجزئية ـ وقد تأثر بهذا المنهج وطوره فيمـا بعد عالم الكيمياء جابر بن حيان فقد تخطى مرحلة الملاحظة في دراسة الظواهر الجزئية وتجاوز مرحلة التجربة التي كان يطلق عليها اسم التجريب وناقداً

القياس الأرسطي ، ملحقاً الفروض بالمنهج التجريبي على الرغم من تردده في تطبيق جزء منها. (· ب)

\section{عمس النهضة العلمية:ة}

بدأت بوادر التفكير العلمي ونهضة العلم والمعرفة والفلسفة أيضـاً مسع عصر جديد كان أغلب المفكرين فيه مشتركين في الاستيلاء من أهداف علم القرون الوسطى بـاحثين عن المعـارف بكافـة فرو عها و أنو اعها

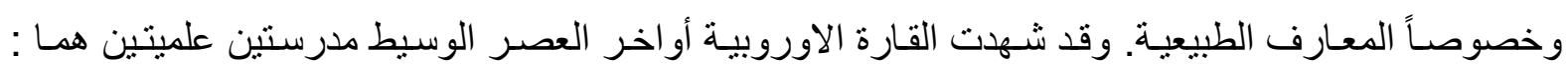

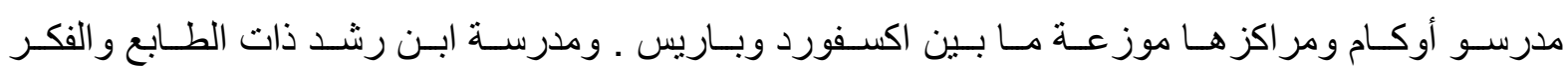

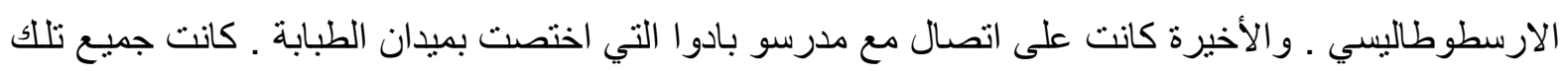
المدارس قد تقدمت علمياً بالاستناد الى نقد ايجابي لفلسفة أرسطو الطبيعيـة واستبدالها بقوانين ونظريـات جديدة 
متعلقة بالحركة ( نظرية الحركة ) ـ وقانون الاستمر ارية. ولم تكن تلك الانجاز ات الا بمثابة ابتعـادات جزئية

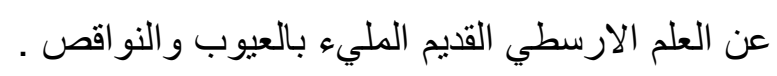

رافق جميع ذلك حركة متسار عة تمثلت بالاهتمام بالتراث اليوناني القديم الذي تمثل ببعث الآداب القديمـة

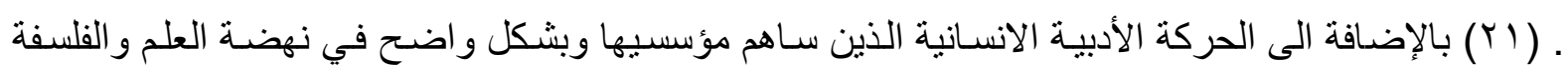
آنذالك اذ دفعوا الناس الى دراسة اصول العلم القديم ، وقد أدت عودتهم الى علىم الأقدمين وخصوصـاً الى على

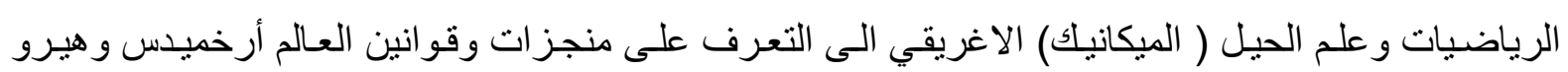
و المهندس العبقري اقليدس ـ فالتقدم الهائل في تلك الميادين كان له أثره الكبير في تقدم العلم وتطويره ـ. وكـان أهم انجـاز في تلك الحقبـة المهــة هو الثورة التي أحدثها عـالم الفلك البولوني كوبرنيكوس ت (Tـ إم) الفلكي الجديد حـول مركزيـة الثـمس بـدلاً مـن نظريـة مركزيـة الأرض لعـالم الفلك اليونـاني القديم بطليموس ـ فقد جاءت النظريـة الفلكيـة الجديدة لتصحح مسـار تلك النظريـة الخاطئة ولتفتح طريقاً جديداً نحو تتظيم ومنهجية جديدة للعلم ، وتو الت الكثوفات في حينها الواحدة تلو الاخرى انطلاقاً من ثورة الفلك الجديدة

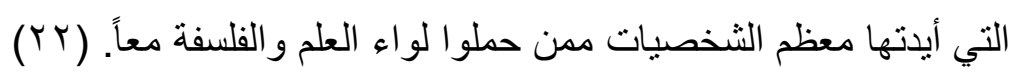
وقد عُرف عن ذللك بأنه عصر صر اع هيمن على الحياة الفكرية الاوروبية ، عصر صر اع بين القدامى و المحدثين . عصر نهضة حداثوية امتدت الى القرن الثامن عثر ـ وقد حدث على أثر تلك النهضـة العديد من العلماء والفلاسفة الذين كانت اسهاماتهم العامل الأكبر الذي كان من بينهم و اشهر هم هو روجر بيكون الذي حمل

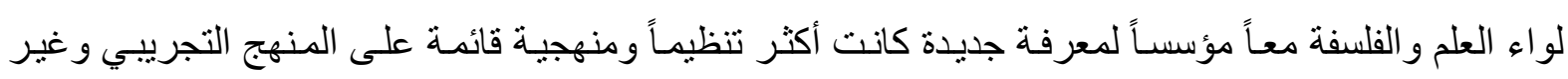

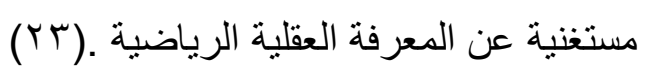

فقد كان روجر بيكون واحداً من سلسلة الباحثين الفرنسيسكان الذي أدى تأثنير هم العلمي الى بدء انهيار أساليب التفكير السائدة في العصور الوسطى ـ اذ ساهم وبشكل كبير في نهضة العلم وفي القضاء على كل ما هو

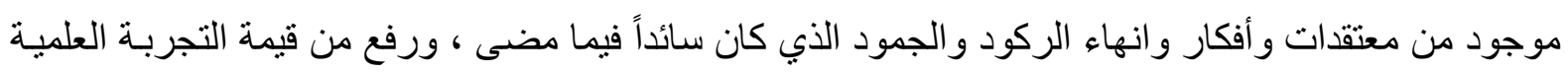

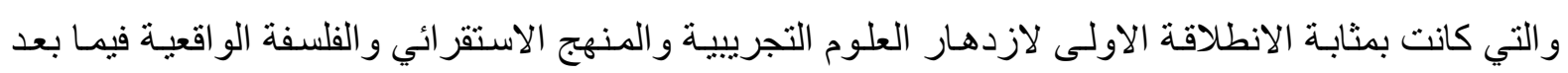

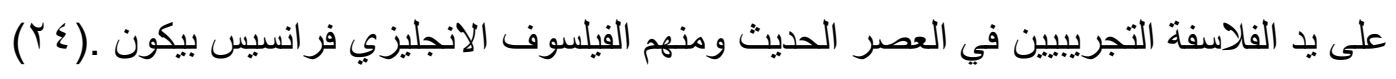

\section{منهوية العلم في العصر العديث:}

امتاز العصر الحديث عن العصور القديمة بأنهه عصر تحققت فيه أعظم الانجازات العلميـة ، فلم تكن وجهة الفكر فيه الا امتداد لتفكير عصر النهضـة كونها ثورة على السلطة العلميـة المتمثلة بسلطة أرسطو (العلم القديم) ، وثورة على السلطة الدينية المتمثلة بسلطة رجال الكنيسة في السيطرة على زمام الامور الدنيويـة. ولم

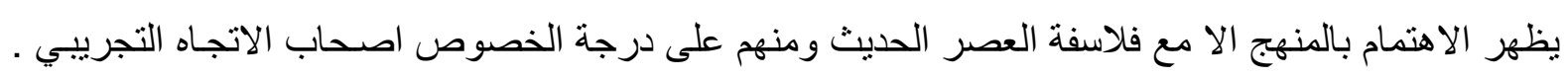
فقد انصرف الفكر الحديث الى الطبيعة والعلوم التي تبحث فيها ونظر اليها نظرةً موضوعية غير متحيزة ، وقويت الرغبة في التعرف على العالم من جديد ـ ولم تكن الفلسفة الحديثة طبيعيـة فحسب ، بل كانت ذات طابع فردي متميز ـ فمن خو اصها لفت عقل الفرد وتحريره من رق القيود التي فرضت عليه من قبل اصحاب السلطة 
والقساوسة ، فقد كان أحد أهم أهداف الحركة الحديثة هو تقرير حق الأفر اد في الحُكم على الأشياء ـ فكل فرد لـه الحف في أن يبحث وينتقد غير مقيد في ذلك بأي سلطة خارجية ، و على هذا الأساس نشأت الفلسفة الحديثة أوائل

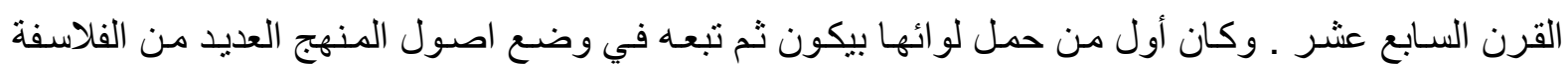
التجريبيين و الفلاسفة العقليين ـ (Yo) وسوف يقتصر بحثي هنا على المنهج التجريبي تحديداً عند بيكون ولوك و آثار منهجها في الحقبة المعاصرة على الكثير من العلوم منها الانجاز ات المعاصرة في ميدان علم الكيمياء وتحضير المستحضرات الطبية .

وقد تجسدت روح البحث العلمي والمنهج التجريبي القائم عل أسس الاستقراء في أنثر كتب بيكون و همـا كتابا : النهوض بالعلم Advanced of Learning وكتاب الاورجانون الجديد Novum Organum ، وان هذان الكتابـان قد عكسـا روح التجديد الفكري الخـلاق بانبثاق منهجيـة البحث العلمي المنظم ذو الطـابع الفلسفي الفكري ـ معبراً فيها عن طرق اقتناص الثوارد و الظواهر من الطبيعة واخضاعها للتجريب ـ وكان من

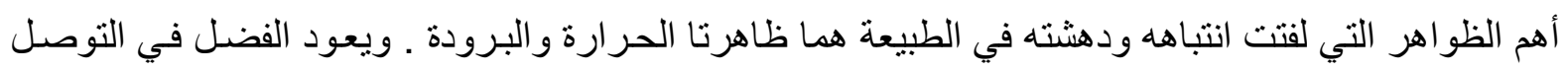
الى علة هاتين الظاهرتين الى فر انسيس بيكون ومنهجية التجريبي .

ولم يكن بيكون ليؤسس لهذا المنهج الا بعد نقده وتحديده نو اقص القياس الأرسطي القديم ليشرع بعدها بإدر اج القو ائم التي ضمها منهجه وقو اعده التسعة ذات الأساس التجريبي المحض. (T ب) فلم يكن القياس القديم

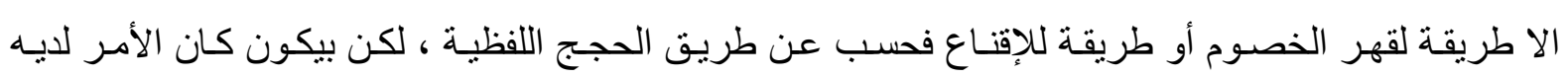
معكوساً تماماً ، فمنهجه التجريبي جاء لقهر الطبيعة وليس الخصوم ومحاولة اكتنـاف كنهها ومكنوناتها بهدف

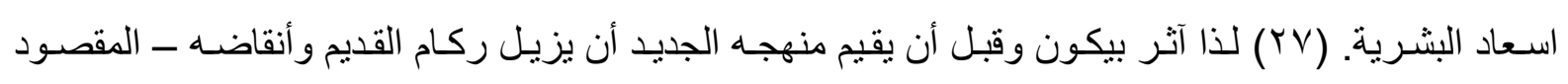

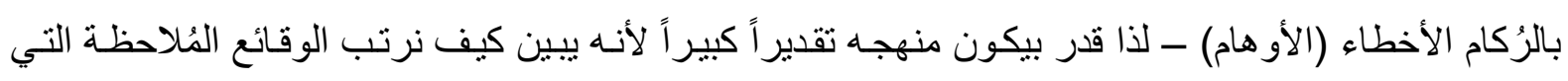
يجب أن يؤسس عليها العلم ـ ولم يغفل دور العقل أيضـاً الى جانب التجريب بل ترك له عملية التنظيم ـ فهو

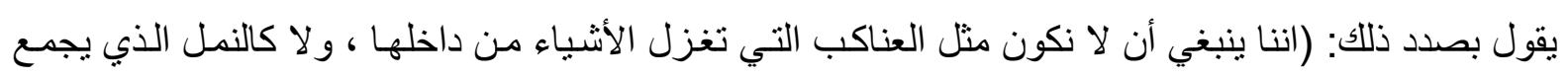

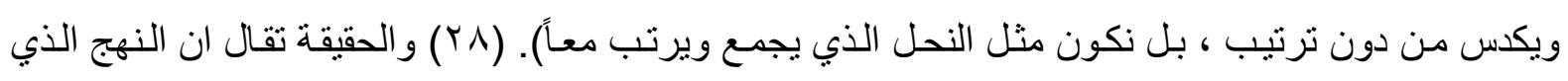

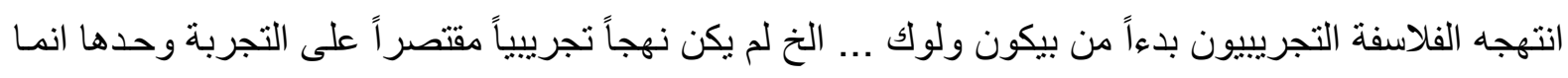

\section{أعطى لها الأولوية ، ومنح للعقل دوراً ثانوياً فاعلاً أيضاً.}

\section{الإنهمج التجريبي وملاقته بنظرية المعرفة عند جون لوك:}

كان جون لوك شخصية فريدة من نوعها في زمانـه ، فهو أحد الفلاسفة الذين جمعوا مـا بين الطـابع

الفلسفي والطـابع العلمي في العصر الحديث ــ وقد سـار هذا الفيلسوف على نهج بيكون في تأصيل وتأسيس

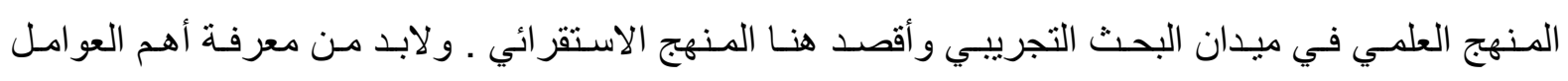

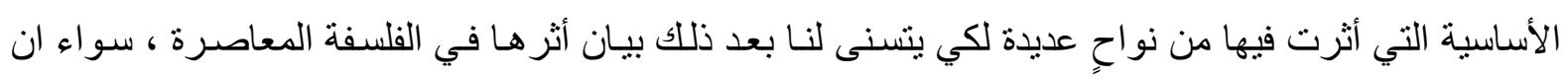

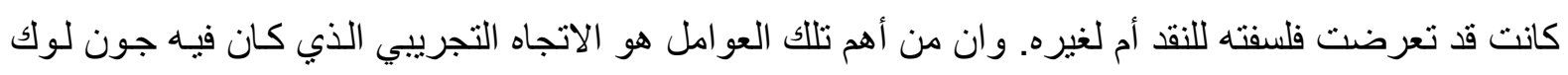


تحست تـأثير بيكون و غـاليليو وهـوبز ، وهو اتجـاه تجريبي - علمي مصسبوغ بالصسبة الحسية ، أي بالعامل التجريبي.

أما الاتجاه الثاني فهو الاتجاه العقلي فهو الاتجاه العقلي المصبوغ بالصبغة المثالية الميتافيزيقية. وقد كان الاتجاه الأول هو الاتجاه السائد و الغالب في أكثر مؤلفاتـه والتي كان من أنتهر ها ( مقالة عن الفهم الانسـي اني ) الذي نشر في عـام • 79 (م. ويعد هذا الكتاب من أهم كتبه على الاطلاق ـ وضـح فيه نقده للأفكار و المبادئ الفطرية التي اعتنقها معظم الفلاسفة العقليين ان لم نقل جميعهم. كما بين في المؤلف ذاته المعرفة التجريبية واختلافها عن المعارف الاخرى مستعرضاً في الوقت نفسه مصادر كل منها ـ وبعدها طرح نظريته في المعرفة و علاقتها بالمنهج التجريبي مؤكداً على أهمية ذلك المنهج في تحقيق نتائج كبيرة في المستقبل القريب - بحسب اعتقاده - في ميدان العلوم التجرييية ( العلوم الطبيعية ) - هذه المسألة التي سوف نركز عليها في سياق بحثنا

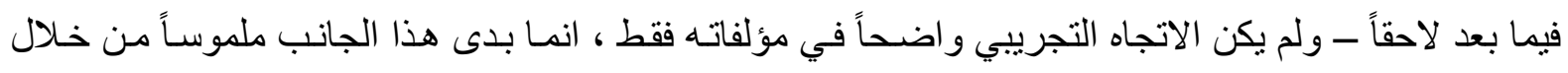
أفكاره الفلسفية التي كان بار عاً في عرضها بعد أن تمكن من بلورة العناصـر التجريبيـة في الفلسفة اليونانيـة القديمة والاتجاهات التجريبية العلمية عند بيكون ، و الاتجاهات الحسية عند جاسندي وهوبز ممزوجـة بـالمنهج

الثكي عند ديكارت ، وقدمها لوك على شكل فلسفة نقدية تجريبية حاله في ذلك حال فر انسيس بيكون. (Y9) ذلك النقد البناء الذي كانت الغايـة منه هو تقديم معرفة متقدمة نحو المزيد من الابداع خدمـةً للبشرية . و على الرغم من الذي وجـه من قبل بعض الفلاسفة التجريبيين أنفسهم الـى الاستقراء ومؤسسيه يبقى المنهج الفعال في صميم تطور العلوم التجرييية . فالنقد الذي وجهه هيوم لاستقر اء الفلاسفة التجريبيين الذين سبقوه

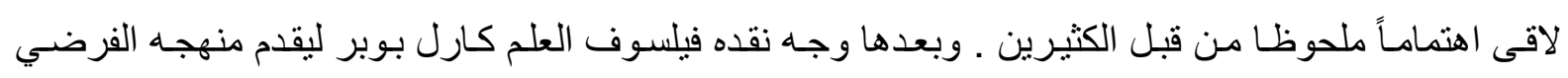
الاستنباطي وليدحض به منهج الاستقراء التجريبي.

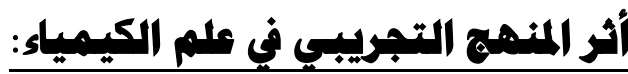

على الرغم من جميع الانتقادات التي وجهت الى المنهج الاستقرائي ، نقول انه قد تحول او تعرض الى نقلة وتحول عالي جداً على يد فيلسوف العلم برنـارد الذي كان السبب الرئيسي في احداث تلك النقلة وحول طابعه من الجانب الفلسفي الى الجانب العلمي المحض. وهذا ما تجلى بوضوح في كتابـه الثــير ( المدخل الى بـ در اسة الطب التجريبي ) . فقد ضم هذا المؤلف در اسـة تجريبية في ميدان الطب ، طبق على أثرها خطوات

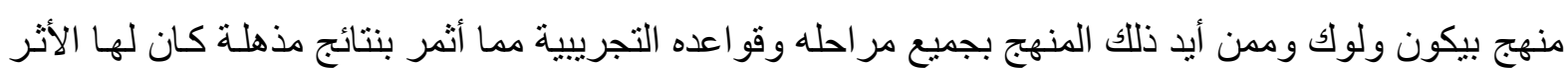
البـالغ في ميدان علم الكيميـاء وفي صناعة الأدويـة والعقاقير الطبيـة واكتشـاف العديد من الأمـر اض و البكتريـا لاسيما بكتريا البنسلين والتي جاءت كأحد الكثوفات العلمية التي تحققت على أحد العلماء بالاعتماد على المنهج التجريبي ذلك العالم الالماني فليمنج الذي قام باستنبات انواع كثيرة من البكتريـا المسببة للعديد من الامر اض بل

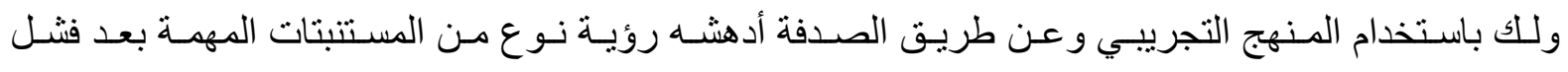
المحاو لات لمرات عديدة ـ لكن الظروف البيئية العرضية غير المقصودة سـاعدت في استنبات مـا اهمل بعضـا

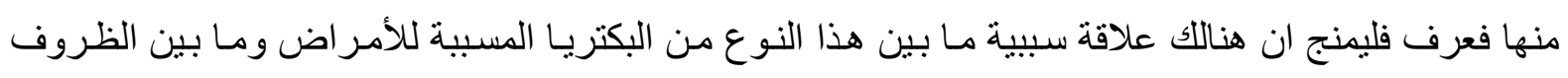


البيئية التي ساهت في انبات ذلك النوع وبعدها وبنفس المنهج استطاع هذا العـالم اكتشـاف عقار البنسلين في الطبابة. ( • (r)

|الخاتمـهـة:

ان المعرفة بـأت بسيطة وسـاذجة ، سـادها الجانب الاسطوري ـ الميثولوجي ، وان هذا الأمر هو مـا ألفناه عند شعوب وسكان الحضار ات القديمة في الثرق ـ وان هذا الطابع الاسطوري لم يأتي من فراغ ، انمـا

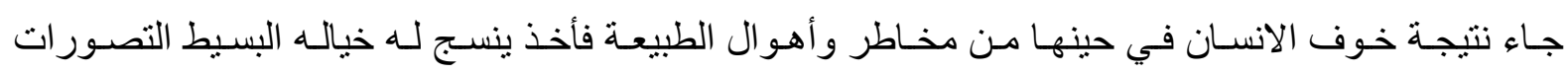
و الخيالات المتعددة ، وفي الوقت نفسه أخذ يبحث عما يبعث السكينة و الهدوء في نفسه ـ. فاعتقد بوجود العديد من

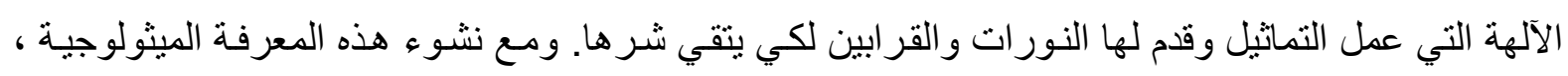

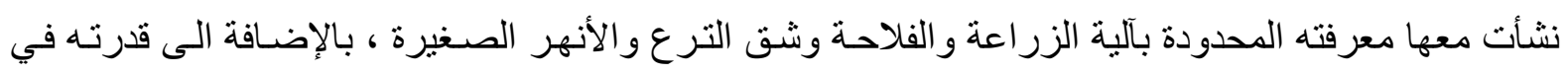

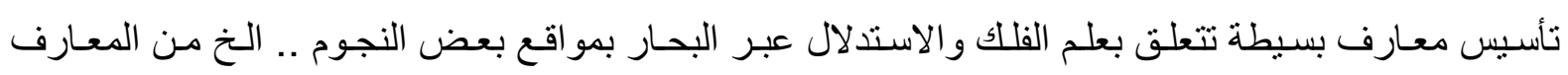
الاخرى .

ولهذا السبب نجد أن المعرفة نشأت ذات طابع اسطوري ـ عملي في الوقت ذاته ـ ولم تكن لديهم منهجيـة محددة و لا أساليب علمية مقننة تعمل على تنظيم معارفهم ـ و هم غير ملومين في ذلك نظر اً لمحدوديـة ومعارفهر

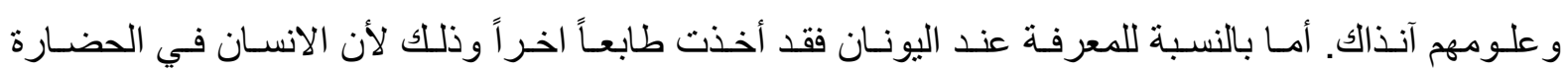
الاغريقية كان أكثر و اقعية نوعاء ما والفروض و التفسيرات التي كان يقدمها بعيدة عن الخيال على الرغم من عدم تخليها تماماً عن العنصر الميثولوجي. ومع هذا كله فان بوادر نشوء المعرفة والعلم المنظم قد ظهر عند

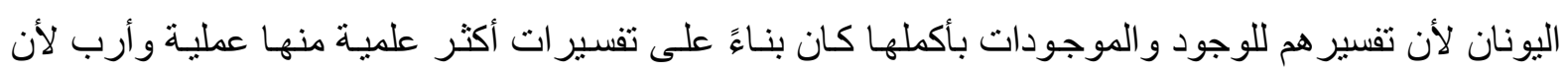
تكون محاكيه للو اقع التجريبي. ولهذا السبب فقد نشأت لديهم العديد من المدارس و المذاهب القديمـة التي كانت الأساس في ظهور العديد من التيارات والاتجاهات الحديثة و المعاصرة فيمـا بعد الفلاسفة الذين نظموا المعرفة وصنفو ها لتأخذ مسار ها التقدمي عبر التأريخ فيما بعد. أما في العصور الوسطى فقد ظلت المعرفة مرتبطة بالدين ولم تخرج عن اطلاره ولم يكن للفلسفة والعلم الدور الكبير نظر اً لسيطرة رجال الكنيسة على تلك الحقبة التأريخية من جانب ، وسطوة العلم الارسطوطاليسي بلي وني

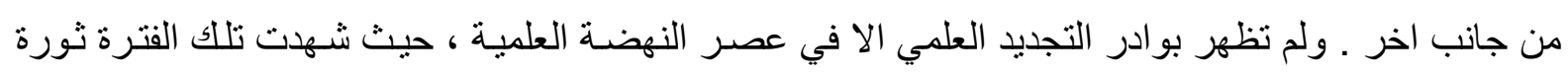
دينية و علمية أحدثت تغير ا جذريا في المفاهيم و العلوم القديمة ـ وكان من أهم نتاجات تلك الحقبة ظهور المنهج على يد عدد من الفلاسفة والعلماء ، لا سيما المنهج التجريبي ثم المنهج العقلي و غيره من المناهج الاخرى التي وني لم تقل عنهما أهمية ـ وقد حقق المنهج التجريبي الكثير من الانجازات القيمة على يد الفلاسفة ثم بدأ يأخذ منحسيً أكثر علمية وو اقعية على يد العلماء ليدخل في ميادين تخصصية دقيقة ذات طابع علمي صرف وفئ ومنها ميدان الطب ـ فاكتثـاف بكتريـا البنسلين واستخدامه في تحضير عقاقير طبيـة وذلك بالاعتمـاد على المنهج العلمي التجريبي كان بمثابة خطوة حاسمة في فتح آفاق مستقبلية جديدة نحو المزيد من العقاقير الطبية والمستحضر ات الاخرى. 


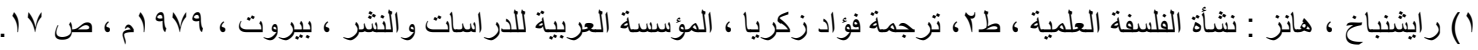

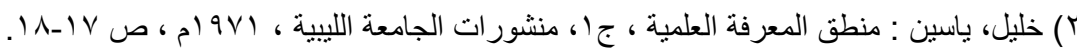

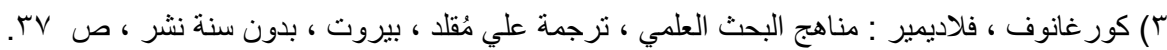

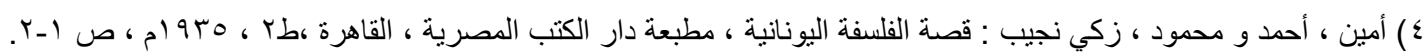

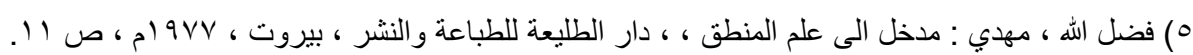

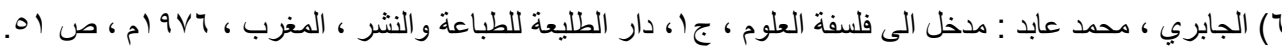

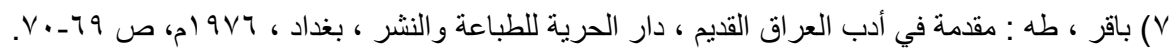

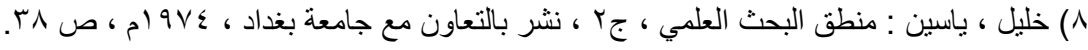

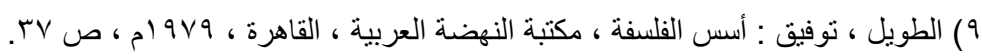

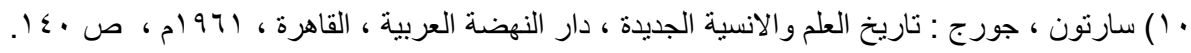

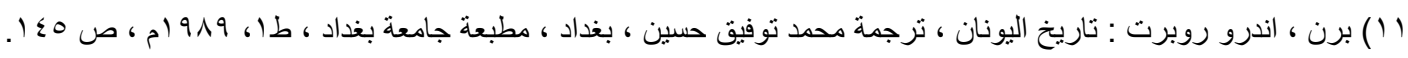

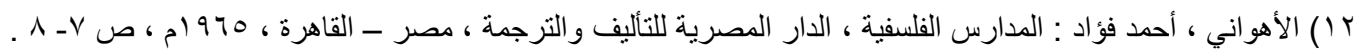

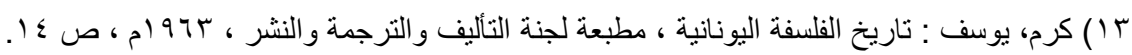

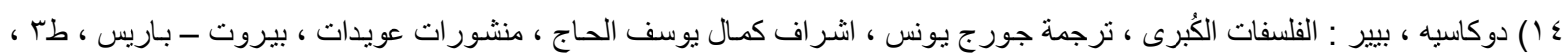

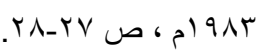
(1) ) راندال ، جون هرمان : تكوين العقل الحديث ، جا ، ، ترجمة جورج طعمة ، مر اجعة برهان الدين الدجاني ، تقديم محمد حسين هيكل ، دار

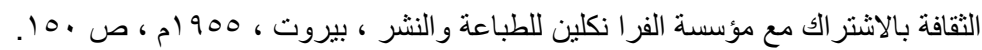

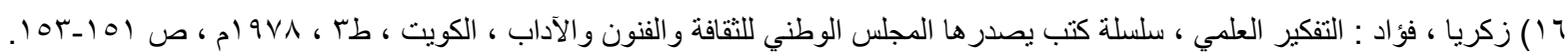

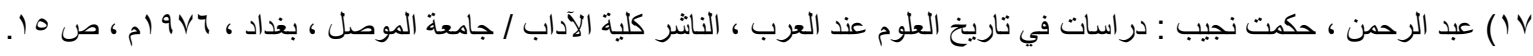

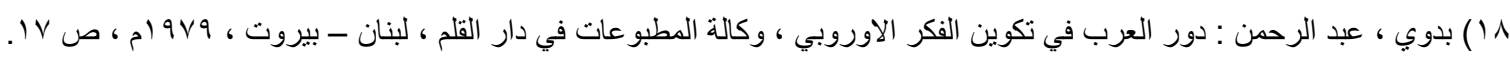
9 ( ) عبد الرحمن ، حكمت نجيب : دراسات في تاريخ العلوم عند العرب ( مقدمة المؤلف )، ص صو 9.

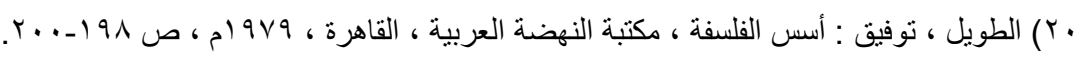

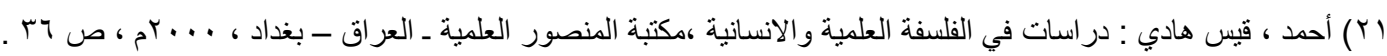

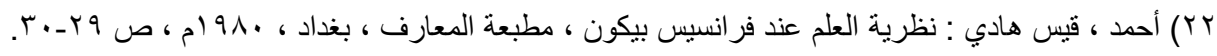

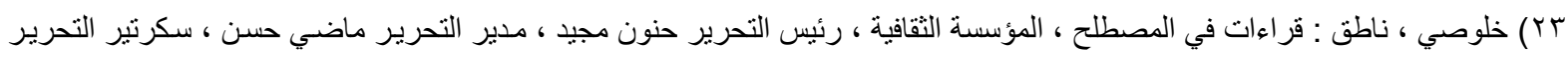

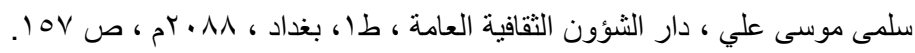

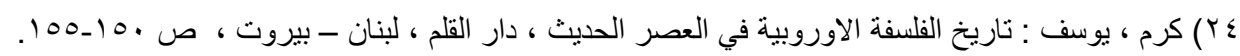

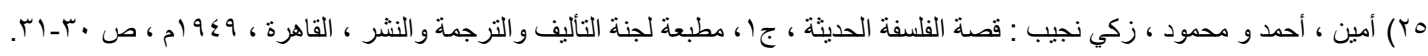

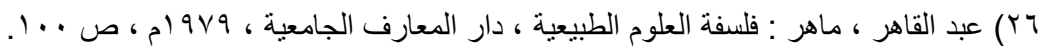

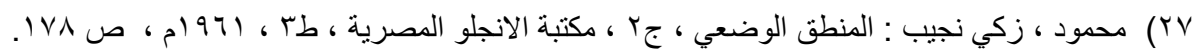

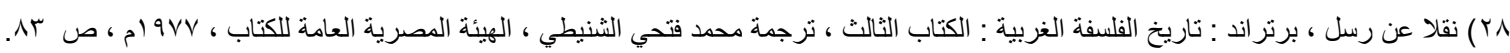

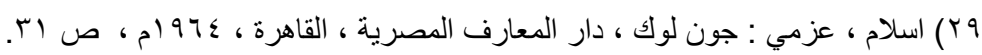

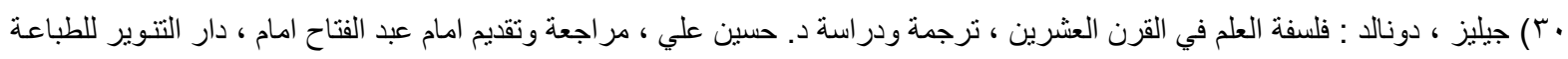

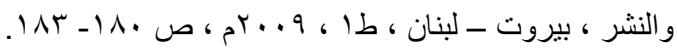

قانُمة الإسادر: 1 أحمد ، قيس هادي : در اسات في الفلسفة العلمية والانسانية ،مكتبة المنصور العلمية ـ العراق ـ بغداد ، ... بrم.

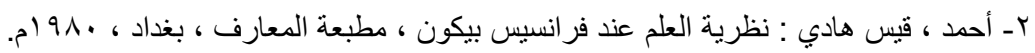

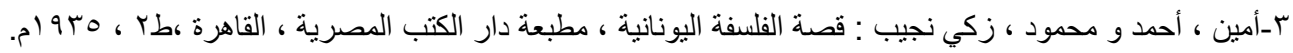
عـ أمين ، أحمد و محمود ، زكي نجيب : قصة الفلسفة الحديثة ، جا ، مطبعة لجنة التأليف و الترجمة والنشر ، القاهرة ، 9 ، 9 ام .

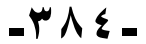




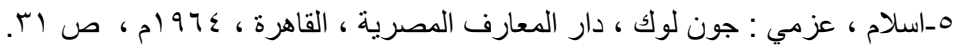

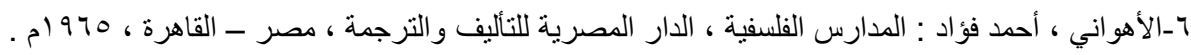

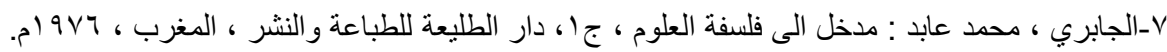

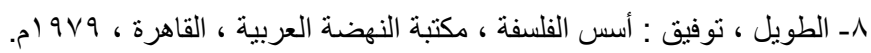

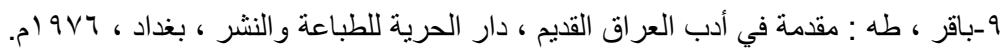

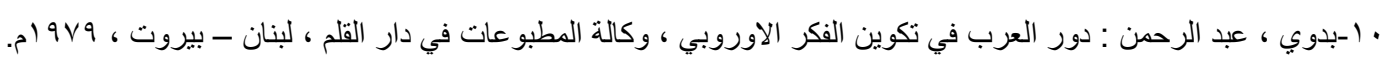

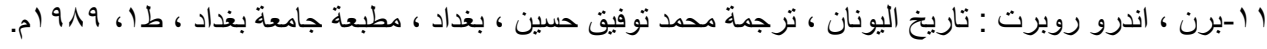

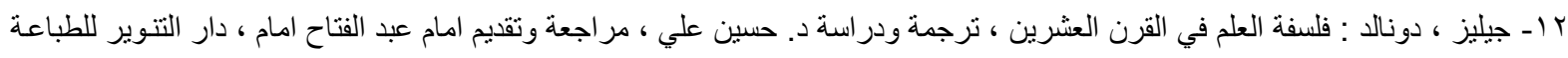

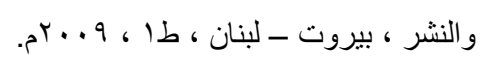

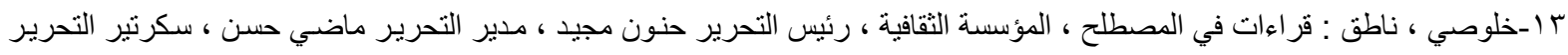

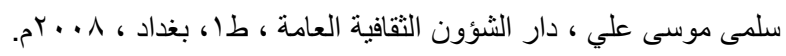

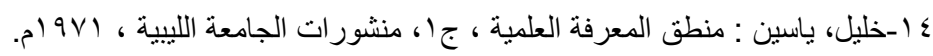

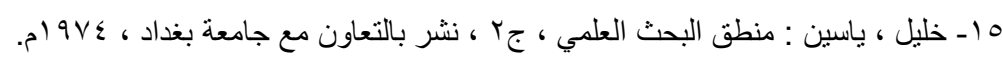

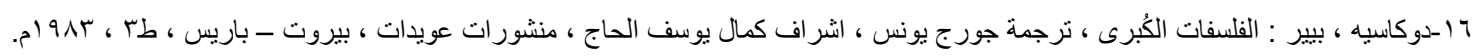

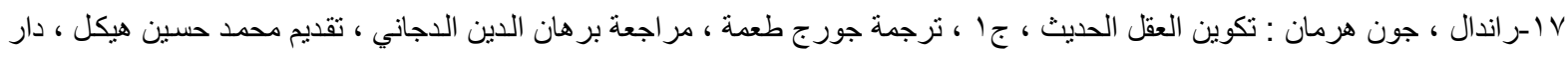

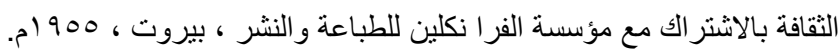

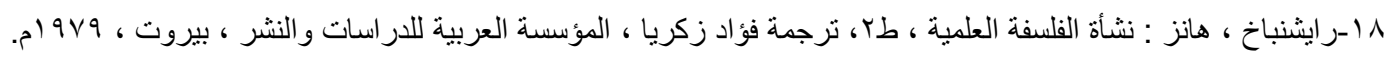

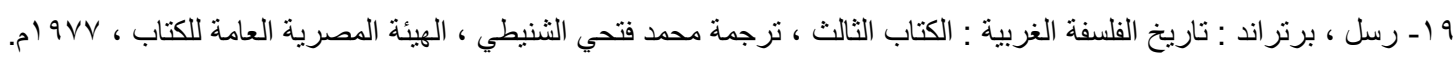

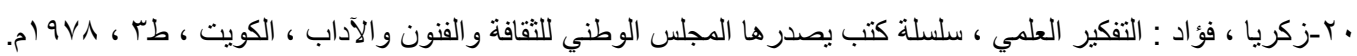

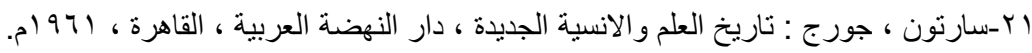
r r-عبد الرحمن ، حكمت نجيب : دراسات في تاريخ العلوم عند العرب ( مقدمة المؤلف ) ).

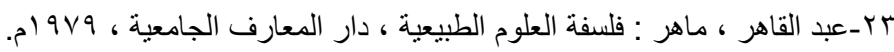

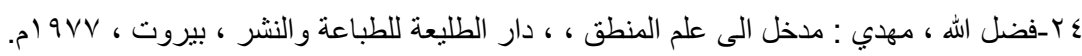

0r-كرم ، يوسف : تاريخ الفلسفة الاوروبية في العصر الحديث ، دار القلم ، لبنان - بيروت.

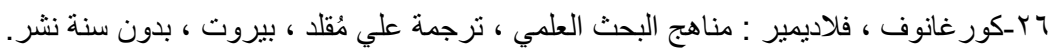

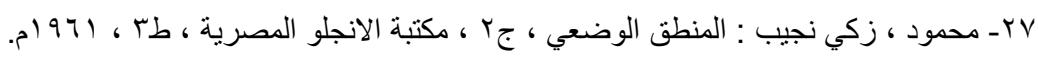

